National Marine

Fisheries Service

NOAA
Fishery Bulletin

a established in 1881 a
Spencer F. Baird

First U.S. Commissione of Fisheries and founder of Fishery Bulletin

\begin{abstract}
We assessed the utility of an alternative method of video analysis for generating data for sharks and compared observations of sharks from the use of baited remote underwater video stations (BRUVS) with observations made by scuba divers during surveys conducted simultaneously with BRUVS video recordings. Videos were made off east-central Florida as part of a fishery-independent trap-video survey of fish species in hard-bottom reef habitats. In videos from 25 of 72 sites, we observed sharks, including the nurse (Ginglymostoma cirratum), tiger (Galeocerdo cuvier), spinner (Carcharhinus brevipinna), sandbar (C. plumbeus), Atlantic sharpnose (Rhizoprionodon terraenovae), bull (C. leucas), and lemon (Negaprion brevirostris) sharks. In contrast, divers observed 3 species of sharks at 5 sites. We conclude that video observations are superior to diver observations for detecting sharks. Rapidly viewing an entire video (the alternative method), rather than viewing only a 20 -min segment (the standard protocol), has the potential to increase the number of sites where sharks are observed and the number of shark species that are observed in video analysis (as it did, by $400 \%$ and $40 \%$, respectively, in this study). This method holds promise for providing critical information without extraction of specimens and for aiding stock assessments and essential fish habitat delineation for these important predators.
\end{abstract}

Manuscript submitted 24 August 2018. Manuscript accepted 12 April 2019. Fish. Bull. 117:87-96 (2019).

Online publication date: 26 April 2019. doi: 10.7755/FB.117.1-2.10

The views and opinions expressed or implied in this article are those of the author (or authors) and do not necessarily reflect the position of the National Marine Fisheries Service, NOAA.

\title{
Comparison of video and diver observations of sharks from a fishery-independent trap-video survey off east-central Florida, including utility of an alternative method of video analysis
}

\author{
Roldan C. Muñoz (contact author) \\ Michael L. Burton \\ Email address for contact author: roldan.munoz@noaa.gov \\ Beaufort Laboratory \\ Southeast Fisheries Science Center \\ National Marine Fisheries Service, NOAA \\ 101 Pivers Island Road \\ Beaufort, North Carolina 28516
}

Predation is recognized as a key ecological and evolutionary process, and sharks, a group that includes species capable of being the top predators in oceans, are important members of marine communities (Estes et al., 2011; Osgood and Baum, 2015; Barley et al., 2017). Sharks are capable of exerting top-down effects on prey from lower trophic levels over wide spatial and temporal scales (Osgood and Baum, 2015; Barley et al., 2017; Dulvy et al., 2017), and shark species are valuable targets of recreational and commercial fisheries. To help protect species that have relatively low reproductive rates, late maturity, and slow growth, the United States has implemented shark management measures that are some of the strongest worldwide $\left(\mathrm{NMFS}^{1}\right)$. Despite conservation efforts, global bycatch of sharks and demand for shark fins and meat have resulted in $\sim 25 \%$ of shark species listed as endangered, vulnerable, or near threatened by the International Union for Con-

${ }^{1}$ NMFS (National Marine Fisheries Service). 2017. 2016 shark finning report to Congress, 117 p. [Available from website]. servation of Nature (IUCN) in the IUCN Red List of Threatened Species (Heithaus et al., 2010; Dulvy et al., 2014; White et al., 2015; WardPaige, 2017), although recent analyses indicate preliminary recovery of certain stocks of sharks in U.S. waters of the Atlantic Ocean (Peterson et al., 2017). We lack even basic biological information for many sharks and their relatives, such that $46 \%$ of species on the IUCN Red List are classified as data deficient (Heithaus et al., 2010; Dulvy et al., 2014; White et al., 2015; Peterson et al., 2017).

Whereas fishery-independent surveys can provide valuable measures of relative abundance to inform stock assessments, one of the hindrances to accurate assessment of shark populations is the lack of fisheryindependent surveys that are done on a stock-wide basis. The NOAA Northeast Fisheries Science Center conducts a biannual longline survey from the Gulf of Mexico to southern New England, and the NOAA Southeast Fisheries Science Center conducts an annual longline survey off the southeastern United States in the Atlantic Ocean and Gulf of Mexico. Although other fishery-in- 
dependent surveys for sharks exist, most of them are spatially limited (Peterson et al., 2017).

The Southeast Reef Fish Survey (SERFS) is a fishery-independent monitoring and research program that targets reef fish species in continental shelf waters off the southeastern United States and is funded by the National Marine Fisheries Service. Annual sampling of this collaborative program, for which the Beaufort Laboratory of the Southeast Fisheries Science Center is a contributor, is done by using video cameras attached to chevron traps to survey a region from St. Lucie Inlet, Florida, to Cape Hatteras, North Carolina (Bacheler et al., 2014). This fishery-independent trap-video survey generates $\sim 1500$ video recordings, or samples, per year and targets species from hard substrates (limestone or hard-bottom reefs) on the continental shelf and continental shelf break of the southeastern United States. Because of time and personnel constraints, SERFS staff primarily evaluate videos for assessment of spatial distribution of reef fish species in the snapper-grouper complex and use a video-sampling method that involves viewing a subset of frames (number of frames $[n]=41$ ) from each video sample to calculate relative abundance (Bacheler et al., 2014; Schobernd et al., 2014). This video-sampling method may not be effective for species, such as sharks, that tend to be relatively rare or highly mobile (Schobernd et al., 2014; Bacheler and Shertzer, 2015).

Video is increasingly used as a fish survey and research tool in marine ecosystem research (see the review by Murphy and Jenkins, 2010), including for the study of elasmobranchs (Meekan and Cappo, 2004; Bond et al., 2012; White et al., 2013; Barley et al., 2017). The advantages of the use of remotely viewable underwater video (often recorded by cameras on baited stations) over traditional, direct underwater visual census (UVC) by scuba divers include the potential for longer survey times, removal of diver effects (attraction or avoidance) on target species (Kulbicki, 1998), and greater depth range and spatial replication. Particularly for relatively rare, large, and mobile species, such as elasmobranchs, UVC may produce biased estimates of population density (MacNeil et al., 2008; Ward-Paige et al., 2010; McCauley et al., 2012; Osgood and Baum, 2015).

The work described in this paper was conducted as part of a study (Bacheler et al., 2017) that compared observations of reef fish abundance from 3 techniques: diver census, video analysis, and sampling with traps (sampling of videos and traps was conducted with SERFS methods). The objective of the work reported here was to assess the utility of an alternative, rapid method of video analysis for generating data specifically for sharks. For this assessment, we used video recordings collected from sampling locations used by Bacheler et al. (2017). We determined species composition and relative abundance of sharks encountered in the Atlantic Ocean off east-central Florida by using UVC conducted by divers and analysis of videos from baited remote underwater video stations (BRUVS), and we compared our results with those of Bacheler et al. (2017). Given that diver and video methods are known to sample different members of fish communities (Colton and Swearer, 2010; Langlois et al., 2010; Watson et al., 2010; Barley et al., 2017), we also specifically compared the composition and relative abundance of shark species observed with these sampling approaches. The SERFS was designed to sample relatively sedentary reef fish species at a regional scale with a large number of sites across the continental shelf of the southeastern United States. We hypothesized that this work would reveal that the use of video can be a non-consumptive alternative or supplement to traditional sampling methods that require extraction (e.g., with longlines and gillnets) for providing estimates of relative abundance for a variety of sharks in the Atlantic Ocean.

\section{Materials and methods}

\section{Study area}

We conducted our study at a number of hard-bottom reef sites in temperate waters on the U.S. continental shelf off east-central Florida (Fig. 1). The continental shelf along the southeastern United States consists primarily of sand and mud substrates, but patches of hard, rocky reefs in temperate waters are scattered throughout the region and are important habitat for many reef fish species. Specific hard-bottom sites were chosen from sampling locations in the study area of the SERFS (Bacheler et al., 2014) by using 2 criteria: depths safe for diving $(<32 \mathrm{~m})$ and a history of traps catching reef fish. Hard-bottom habitats sampled in our work ranged from rocky ledges to patchily distributed rock outcrops and pavement, sometimes covered in a veneer of sand. All sampling occurred at depths between 18 and $30 \mathrm{~m}$ on 2-7 July 2014 aboard the M/V Spree, a 30.2-m aluminum-hulled vessel converted from use for oil field services to a live-aboard dive platform that was fitted with a pot hauler for this effort.

\section{Chevron traps}

We deployed a single chevron trap at each site sampled in this study. Chevron traps were shaped like an arrowhead and measured $1.7 \mathrm{~m} \times 1.5 \mathrm{~m} \times 0.6 \mathrm{~m}$, with a volume of $\sim 0.91 \mathrm{~m}^{3}$ (Bacheler et al., 2014). The mouth of each trap, shaped like an upside-down teardrop, measured $\sim 45 \mathrm{~cm}$ high and $18 \mathrm{~cm}$ wide, and the mesh size of each trap was $3.4 \mathrm{~cm}^{2}$. We baited each trap with $\sim 4 \mathrm{~kg}$ of menhaden (Brevoortia spp.). A soak time of 90 min was targeted for each trap, but actual soak time varied from 51 to $99 \mathrm{~min}$, with a mean of 80.2 min (standard deviation [SD] 11.2). Each trap had a single 8-mm polypropylene line connecting it to 2 surface floats. Chevron traps were deployed with an average distance of $813 \mathrm{~m}$ separating them to provide some measure of independence between traps. The minimum 


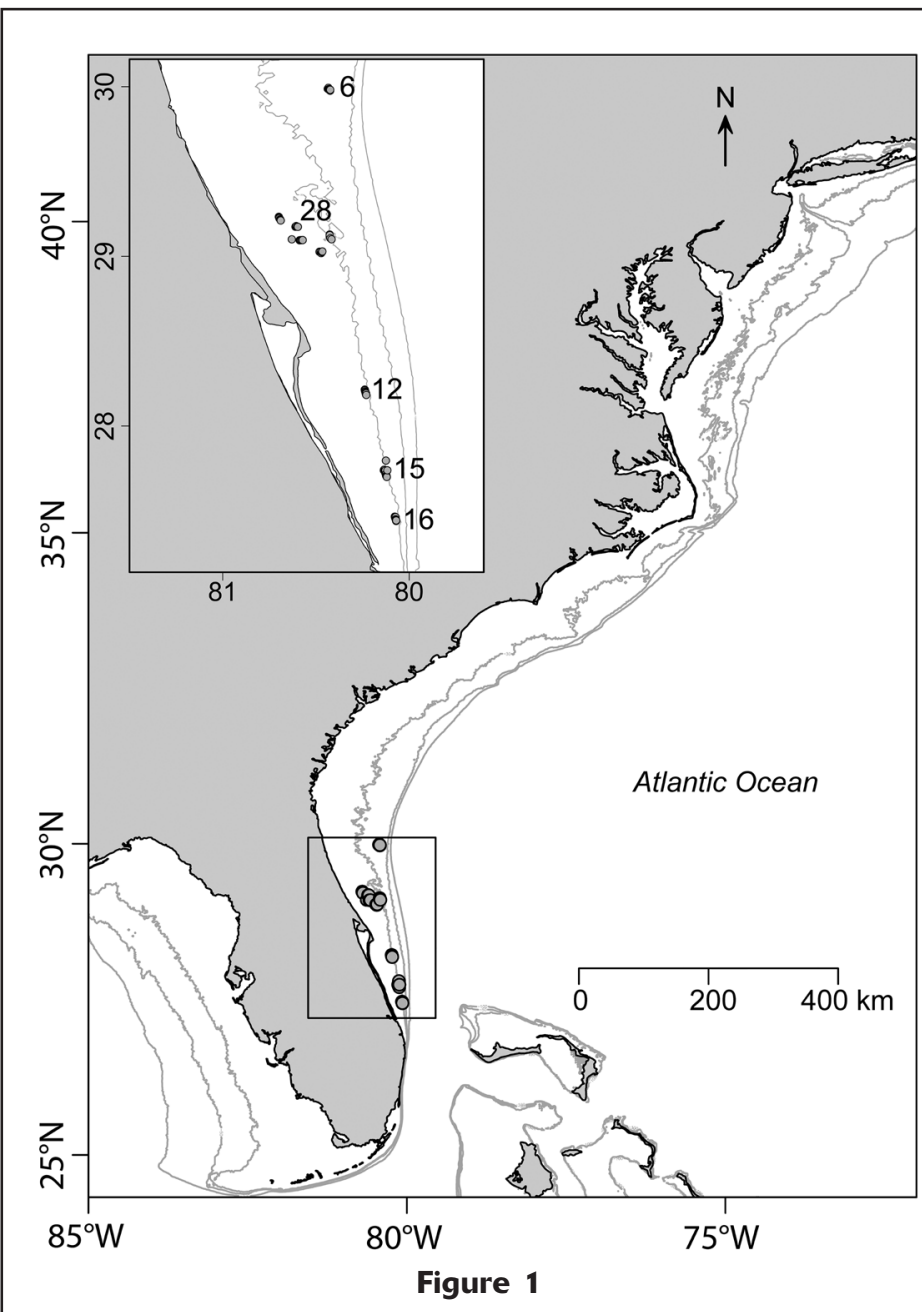

Map of the study area showing the locations of 77 sites off eastcentral Florida where baited remote underwater video stations were deployed and scuba divers conducted underwater visual census to survey shark species in July 2014. The inset map provides the number of sites in each cluster. Note that symbols indicating sampling locations often overlap in both maps. Gray lines in both maps indicate the 30-, 50-, and 100-m isobaths.

distance between 2 traps was $237 \mathrm{~m}$, but these 2 sites were sampled more than $3 \mathrm{~h}$ apart.

\section{Underwater video}

We outfitted each chevron trap with 2 outward-looking video cameras, forming a 2-camera BRUVS. A highdefinition Vixia HF S2002 video camera (Canon U.S.A., Inc., Melville, NY) with a standard lens in an HF-S21 underwater housing (Gates Underwater Products, Inc., Poway, CA) was attached over the mouth of each trap, facing away from the trap. A second high-definition vid-

\footnotetext{
${ }^{2}$ Mention of trade names or commercial companies is for identification purposes only and does not imply endorsement by the National Marine Fisheries Service, NOAA.
}

eo camera (HD HERO4 Black, GoPro, Inc., San Mateo, CA) was attached over the nose of each trap (opposite the Canon camera), also looking outward. The Canon camera was used to record video for quantifying the number of fish at each site (i.e., for video analysis, a single, unique Canon video recording was reviewed for each site). The GoPro camera, which provided additional and sometimes better views of activity at a site if a fish passed closer to it, was used only when necessary to confirm identification of fish species.

Video recordings were $\sim 90 \mathrm{~min}$ in length. The SERFS video-analysis protocol commences 10 min after a trap reaches the seafloor, with fish counted every $30 \mathrm{~s}$ during a $20-\mathrm{min}$ period (or segment) for a total of 41 frames, each $1 \mathrm{~s}$ in duration. For this study, we reviewed videos in their entirety (rather than a subset of fortyone 1-s frames) at a speed that was approximately 2 times faster than the viewing speed used in the standard protocol, using a jog wheel (as part of our video editing hardware setup) for precise control of video speed. The jog wheel allowed us to rapidly review videos without exceeding a maximum rate that would have resulted in skipped video frames and potentially in missed fish detections. All sharks observed were identified (enabling collection of presence-absence data for each species and video recording) and counted, and, when possible, their sex was determined to be male if claspers were observed (sex data not shown). We compared the trap catch between sites with and without video observations of sharks by using a Mann-Whitney $U$ test. We calculated frequency of occurrence for each species as the number of sites with observations of a given shark species divided by the total number of sampled sites.

We compared, using a chi-square test, the proportion of sites with sharks observed during the SERFS 20-min segment with the proportion of sites with sharks observed outside the 20-min segment (i.e., before, or the first $10 \mathrm{~min}$ after the trap reaches the seafloor, and after, or the part of the video from $30 \mathrm{~min}$ after the trap reaches the bottom to the end). Videos with observations of sharks were classified as either outside or within the 20-min segment. Videos classified as outside the 20min segment had shark observations solely outside the segment. Videos classified as within the 20-min segment could include observations outside the segment in addition to observations within the segment, but the 2 classifications were mutually exclusive.

\section{Underwater visual census}

Within 10 min of the deployment of each BRUVS, 2 divers descended along the trap line until they could 
see the trap. Staying at least $15 \mathrm{~m}$ from the trap, divers counted fish and measured habitat features along 3 transects that were each $30 \mathrm{~m}$ long and $10 \mathrm{~m}$ wide (i.e., they surveyed $300 \mathrm{~m}^{2}$ for each transect and 900 $\mathrm{m}^{2}$ at each site). The chosen direction of the first transect was typically toward the part of a site that had the most hard-bottom substrate, beginning $\sim 15 \mathrm{~m}$ from the trap, so that the trap and video sampling were disturbed as little as possible. The second transect was surveyed in the direction opposite of the first transect, and the third transect was perpendicular to the first 2 transects and often contained the least amount of hard-bottom habitat. The depths of habitats sampled by UVC were similar (with differences $<2 \mathrm{~m}$ ) in all cases to the depths at which traps were deployed and, therefore, the depths at which video recordings were made. Further details about the method and full results of UVC can be found in Bacheler et al. (2017).

For the work described in this manuscript, the primary interest in UVC data was whether divers encountered a shark at a particular site and, if they did, the recorded species identification for the sharks observed. We compared the identification of sharks by divers with that from video analysis at those sites where observations were positive for both survey methods. We used a chi-square test to compare the proportion of sites at which sharks were seen by divers with the proportion of sites for which sharks were seen in video analysis. All statistical analyses were conducted with SigmaPlot, vers. 11.0 (Systat Software, Inc., San Jose, CA).

\section{Results}

\section{Species of sharks observed in videos}

We reviewed $100.5 \mathrm{~h}$ of video and observed sharks in videos from 30 of 77 sites. In 5 cases, pairs of sites were located $<500 \mathrm{~m}$ apart, and review of videos from these sites revealed that the same species of sharks were observed at both sites in each pair. Therefore, video recordings from one of the pair of sites (a total of 5 videos) were dropped from further analyses. As a result, 25 of 72 sites with shark observations, or $35 \%$ of videos, were used for analyses. The average length of video recordings was $78.5 \mathrm{~min}$ (SD 6.00). For most sites, a single species of shark was observed, as a solitary individual in video frames. However, for 2 sites, 2 nurse sharks (Ginglymostoma cirratum) were seen at the same time in a single video frame, and 2 Atlantic sharpnose sharks (Rhizoprionodon terraenovae) were seen in a single video frame from another site. In each of 18 videos, 1 species of shark was observed; 6 videos contained 2 species, and 1 video contained 4 species. In all of these analyzed videos, a minimum of 36 individual sharks were observed. At the 25 sites for which sharks were observed in videos, their associated chevron traps contained significantly more fish, with a mean of 71.9 individuals (SD 56.5), than those traps associated with the videos in which sharks were absent, with a mean of 48.4 individuals (SD 49.9) ( $n=47$ sites; Mann-Whitney U test: $U=397, P=0.03$ ). No sharks were captured in traps, and the full results for trap catches can be found in Bacheler et al. (2017).

Seven species of sharks, including the nurse, tiger (Galeocerdo cuvier), spinner (Carcharhinus brevipinna), sandbar (C. plumbeus), Atlantic sharpnose, bull (C. leucas), and lemon (Negaprion brevirostris) sharks, were observed in videos (Fig. 2). Because of water turbidity and proximity of sharks to the camera, we were unable to identify to species carcharhinid sharks observed in videos from 2 sites. In most cases, the sharks that we observed were readily identifiable to species. However, one limitation of any method of analyzing video to sample fish is that taxa are not retained for positive identification.

Frequency of occurrence (Fig. 3) was greatest for the nurse shark, which was observed in videos from $\sim 14 \%$ of sites (10 of 72 sites), followed by the tiger ( $8 \%$, 6 sites), spinner (7\%, 5 sites), sandbar (5\%, 4 sites), and Atlantic sharpnose (4\%, 3 sites) sharks. The bull shark, lemon shark, and sharks identified only to the family Carcharhinidae were observed in videos from $3 \%$ of sites ( 2 of 72 sites).

\section{Comparison of methods}

When the entire video was analyzed, sharks were observed at 4 times more sites than when only the SERFS 20-min segment was analyzed (28\% versus $7 \%$ of the total number of sites, respectively; chi-square test: $\chi^{2}=9.5$, $\left.\mathrm{df}=1, P=0.002\right)$. Sharks frequently were observed in videos classified as outside of the 20-min segment. Of the 25 videos with sharks, 20 videos contained sharks exclusively outside of the 20-min segment, and 5 videos had sharks within the 20 -min segment. Of these 5 videos, 3 videos included sharks that also were observed later in the video outside the 20min segment. Of the 20 videos with sharks observed solely outside the 20 -min segment, 2 videos had sharks before the 20 -min segment (10\%), and 18 videos contained sharks after the segment $(90 \%)$.

Results from analyses of entire videos for sharks were superior to those based on UVC of transects by divers. A greater diversity of sharks were observed and sharks were recorded at a larger number of sites when the alternate video-analysis method was used than when divers used UVC. At 5 sites, sharks were detected both by using the SERFS 20-min video segment and by using UVC, although the individual sites where sharks were detected were mostly (except for 1 site) distinct between methods. By using UVC, 3 species of sharks were recorded at 5 sites ( $7 \%$ of sites, Table 1), and the use of video analysis resulted in observations of 7 species in videos from 25 sites (35\% of sites; chisquare test: $\left.\chi^{2}=15.2, \mathrm{df}=1, P<0.001\right)$. Although a greater diversity of sharks overall was observed by using video analysis than by using UVC, site-specific comparisons of UVC and video data revealed differences in the presence and absence of sharks, as well as in the species of 


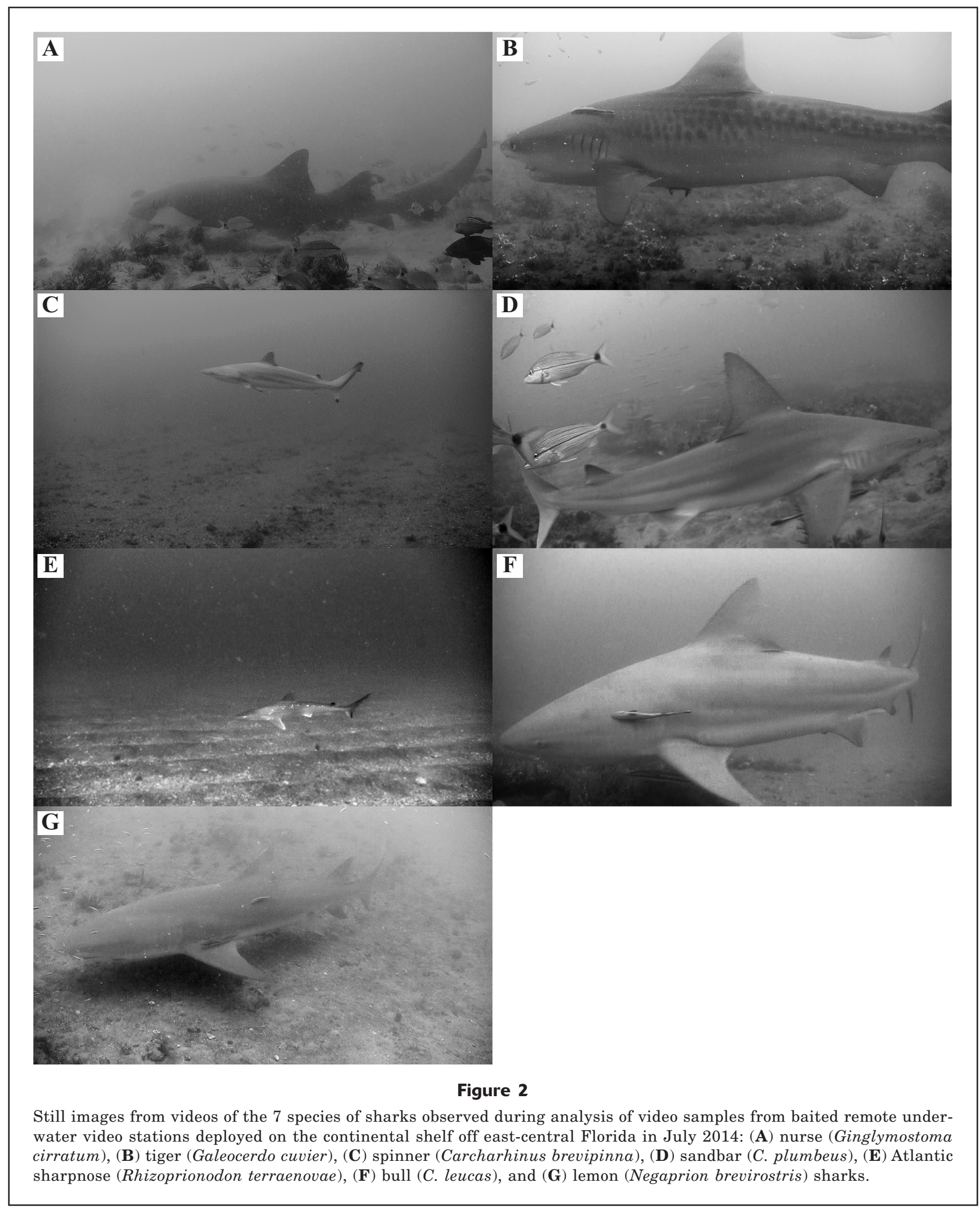




\section{Table 1}

Comparison of observations of shark species between 2 methods used: 1) underwater visual census conducted by scuba divers and 2) analysis of videos taken with baited remote underwater video stations. This comparison includes only observations from the 5 sites at which sharks were detected by divers. Diver surveys and station deployments occurred in July 2014 on the continental shelf off east-central Florida. A dash indicates that a shark was not observed in the video from this site.

\begin{tabular}{lll}
\hline Site number & \multicolumn{1}{c}{ Diver } & \multicolumn{1}{c}{ Video } \\
\hline 10 & Rhizoprionodon terraenovae & - \\
34 & Ginglymostoma cirratum & G. cirratum \\
44 & Carcharhinus plumbeus & G. cirratum \\
55 & G. cirratum & - \\
67 & G. cirratum & G. cirratum, Galeocerdo cuvier \\
\hline
\end{tabular}

corded when the entire video was analyzed. As a result, estimates of rank abundance for shark species differed by the method used (Table 2).

\section{Discussion}

By rapidly analyzing an entire video rather than only the 20 -min subsample required by the SERFS protocol (an average of $58 \mathrm{~min}$ of additional video combined, before and after the subsample), we were able to observe sharks in videos from $400 \%$ more sites and increase the number of species recorded by $40 \%$. Therefore, our estimates of relative abundance for these key fish community members changed

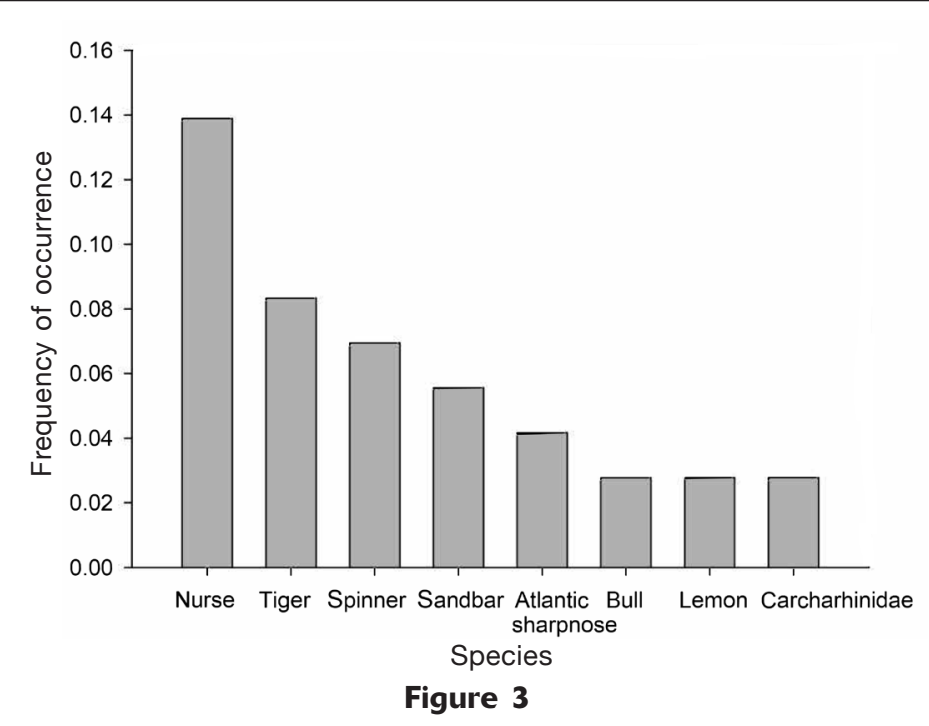

Frequency of occurrence of the 7 shark species observed through analysis of video recorded with baited remote underwater video stations in July 2014 off east-central Florida: nurse (Ginglymostoma cirratum), tiger (Galeocerdo cuvier), spinner (Carcharhinus brevipinna), sandbar (C. plumbeus), Atlantic sharpnose (Rhizoprionodon terraenovae), bull (C. leucas), and lemon (Negaprion brevirostris) sharks. Frequency of occurrence for each species was calculated as the number of sites with observations of a species divided by the total number of sampled sites. Two sharks could be identified only to the level of family (Carcharhinidae). sharks observed through the use of these 2 sampling methods. In some cases, divers observed sharks that were not recorded in videos and vice versa, and in other cases the same species of sharks were observed both by divers and in videos (Table 1 ).

Comparing all 3 methods (entire video analyzed, only SERFS 20-min segment of video analyzed, UVC), a greater diversity and abundance of sharks were re- from those determined by using the SERFS protocol. These findings confirm for species of sharks the results of Bacheler and Shertzer (2015), who suggested that fast-moving, solitary, infrequently encountered fish species had a higher probability of being missed in analysis of video subsamples and recommended increasing the number of video segments reviewed to target these types of species. Similarly, we observed sharks for more sites within the longer intervals (an average of $48 \mathrm{~min}$ of additional video) that followed the SERFS 20-min segments than within other parts of videos, and longer sampling intervals have been associated with increased arrival of targeted species in other studies that used underwater video (Watson, 2006; Watson et al., 2010).

Given the significant costs associated with large-scale marine research surveys, examination of a complete video to gain additional information on large-bodied, less-abundant species, such as sharks, represents a relatively simple way to add significant value to the already successful SERFS (e.g., Link et al., 2008; Mitchell et al., 2014; Bacheler et al., 2016). In addition, the regional coverage of the SERFS, together with habitat and environmental data (e.g., depth, temperature, salinity, pH, turbidity) that are collected annually at a large number of sites ( 1500 sites per year), provides an important opportunity to collect relative abundance and habitat use information on relatively expansive spatial and temporal scales for a variety of shark species found in the Atlantic Ocean. For example, the distribution and biomass of sharks are influenced by physical factors, such as sea-surface temperature, oceanic primary productivity, and reef complexity, and by biological factors, such as competition, reproduction, lower-trophic-level biomass, and prey availability 


\section{Table 2}

Rank relative abundance ${ }^{1}$ of shark species from the use of 3 different sampling methods: analysis of entire video, analysis of a 20 -min subsample of video (41 frames), and underwater visual census (UVC). Scuba divers conducted UVC surveys simultaneously with deployments of baited remote underwater video stations in July 2014 on the continental shelf off east-central Florida. Also provided are frequency of occurrence (FO) from analysis of entire videos and the mean number of individuals observed in video subsamples or by divers over an area of $300 \mathrm{~m}^{2}$. A dash indicates that a species was not observed with this method.

\begin{tabular}{|c|c|c|c|c|c|c|}
\hline \multirow[b]{3}{*}{ Species } & \multicolumn{6}{|c|}{ Sampling method } \\
\hline & \multicolumn{2}{|c|}{$\begin{array}{c}\text { Entire } \\
\text { video analyzed }\end{array}$} & \multicolumn{2}{|c|}{$\begin{array}{c}\text { Subsample of } \\
\text { video analyzed }\end{array}$} & \multicolumn{2}{|c|}{ UVC } \\
\hline & $\begin{array}{c}\text { Rank } \\
\text { relative } \\
\text { abundance }\end{array}$ & $\mathrm{FO}$ & $\begin{array}{c}\text { Rank } \\
\text { relative } \\
\text { abundance }\end{array}$ & $\begin{array}{c}\text { Mean } \\
\text { number of } \\
\text { individuals }\end{array}$ & $\begin{array}{c}\text { Rank } \\
\text { relative } \\
\text { abundance }\end{array}$ & $\begin{array}{c}\text { Mean } \\
\text { number of } \\
\text { individuals }\end{array}$ \\
\hline Ginglymostoma cirratum & 1 & $14 \%$ & 3 & 0.01 & 1 & 0.013 \\
\hline Galeocerdo cuvier & 2 & $8 \%$ & - & - & - & - \\
\hline Carcharhinus brevipinna & 3 & $7 \%$ & 1 & 0.30 & - & - \\
\hline C. plumbeus & 4 & $5 \%$ & 3 & 0.01 & 2 & 0.004 \\
\hline Rhizoprionodon terraenovae & 5 & $4 \%$ & 3 & 0.01 & 2 & 0.004 \\
\hline C. leucas & 6 & $3 \%$ & 2 & 0.03 & - & - \\
\hline Negaprion brevirostris & 6 & $3 \%$ & - & - & - & - \\
\hline
\end{tabular}

(Wirsing et al., 2007; Nadon et al., 2012; Heupel and Simpfendorfer, 2014). In this study, chevron traps associated with videos that recorded sharks contained significantly higher total numbers of individual fish than traps associated with videos in which sharks were absent, a result that may relate to prey availability at sites from which the former videos were collected.

Depending on the relative abundance of shark species encountered at the regional scale, these data could be used to generate species-specific abundance indices for shark stock assessments. Data gathered from video analysis can provide, without the need for extraction of sharks, estimates of relative abundance for a variety of coastal shark species on the continental shelf of the southeastern United States. A standardized, non-destructive method of video analysis can supplement traditional sampling methods (e.g., those that use longlines or gillnets). Brooks et al. (2011) compared estimates of shark relative abundance from the use of BRUVS and longline surveys, found significant positive correlations between methods for the more abundant species, and concluded that the use of videos from BRUVS represented a non-invasive, cost-effective alternative to the use of longlines for monitoring broad trends in the relative abundance of sharks. A sharkdedicated addition to the SERFS would complement the 3 large-scale regional longline surveys of sharks that currently operate in the southeastern United States: Cooperative Atlantic States Shark Pupping and Nursery Survey, Apex Predators Program Large Coastal Shark Survey, and Shark and Red Snapper Bottom
Longline Survey. These surveys tend to have annual sample sizes or areas of coverage that are smaller than and mostly inshore of those of the SERFS.

In our study, 7 species of sharks were observed in videos from 25 of 72 sites ( $35 \%$ of sites). This proportion of sites with sharks is high relative to a regional survey of the entire Great Barrier Reef, off northeastern Australia, that detected sharks in videos collected during $25 \%$ of 2438 BRUVS deployments (Espinoza et al., 2014), likely a result of the limited sample size and spatial coverage of our study. The most common finding in both studies is that a single species of shark was observed at each site. In our study, the nurse shark was observed in greater abundance than other species, followed in descending order by the tiger, spinner, and sandbar sharks. An assessment of population status for the sandbar shark found the stock to be overfished but that overfishing was not occurring (SEDAR, 2017), and the results of recent studies indicate potential recovery since the early 1990s for the tiger, spinner, sandbar, bull, and lemon sharks (Carlson et al., 2012; Peterson et al., 2017). The only other species observed in our study that has been assessed by the National Marine Fisheries Service, the Atlantic sharpnose shark, was not found to be overfished (SEDAR, 2013).

The results of our study support the idea that analysis of videos from BRUVS is superior to the use of UVC by divers for detecting sharks, in agreement with reports from other studies (Meekan and Cappo, 2004; McCauley et al., 2012; Osgood and Baum, 2015; Barley et al., 2017). The use of BRUVS provides 1) a way 
to control for species-specific differences in attraction to or avoidance of divers (Kulbicki, 1998; Watson and Harvey, 2007), 2) superior detection capacity (McCauley et al., 2012), 3) easy deployment at much greater depths and in environments where diver safety may be a concern (De Vos et al., 2015), and 4) longer soak times and sampling intervals because BRUVS are not subject to decompression limits (Watson et al., 2010). Additionally, the lower relative costs and fewer personnel required for deployment of BRUVS, compared with those of large-scale UVC or longline sampling, allow larger sample sizes (Willis et al., 2000; Brooks et al., 2011) and facilitate the deployment of BRUVS at large spatial scales (White et al., 2013; Espinoza et al., 2014; Santana-Garcon et al., 2014). Studies of temperate, subtropical, and coral reefs in Western Australia determined that analysis of videos from BRUVS results in greater species richness and a greater number of targeted, carnivorous large-bodied species, such as those in the families Lethrinidae and Serranidae, whereas UVC conducted by divers results in observations of more site-attached, cryptic small-bodied species, such as some members of the families Pomacentridae, Labridae, and Scaridae (Langlois et al., 2010; Watson et al., 2010). On the other hand, observations in videos from BRUVS may be affected by currents and fish traits, such as appetite and search behavior, as well as by inter- or intraspecific interactions (Stoner et al., 2008; Barley et al., 2017).

In this study, sharks were observed at more sites and with a greater species diversity through analysis of video from BRUVS than with UVC conducted by divers. By using UVC, 3 species of sharks were recorded at 5 sites, but 7 species were observed in videos from BRUVS at 25 sites. Site-specific comparisons of data from the use of BRUVS and UVC revealed differences in the presence and absence of sharks and in the species of sharks observed. These differences may reflect species-specific responses (attraction or avoidance) to the presence of divers versus traps (Kulbicki, 1998; Meekan and Cappo, 2004; Watson and Harvey, 2007). For example, in our study, the tiger shark was not observed by divers but was the second-most abundant shark observed in videos from BRUVS. Meekan and Cappo (2004) also reported that divers rarely encountered hammerhead sharks (Sphyrnidae) and the tiger shark but that those taxa were recorded often in videos from BRUVS. Finally, differences in results between the use of UVC and analysis of videos from BRUVS in our study may reflect the difference in the spatial footprint of habitat sampled with the 2 methods: the area sampled with video recordings was not necessarily a subset of the habitat sampled with UVC, and in some cases there was no overlap at all between the areas covered by the 2 methods (Bacheler et al., 2017).

Sharks fill a key ecosystem role because of their predatory activity. Although some species are capable of feeding at the apex predator level, this group also includes planktivores, scavengers, and mesocarnivores. Sharks have been implicated in control of the abun- dance and biomass of prey in lower trophic levels and in maintenance of biological diversity (Heupel et al., 2014; Osgood and Baum, 2015; Terborgh, 2015; Frisch et al., 2016; Barley et al., 2017). Given that the SERFS annually samples $\sim 1500$ sites across the continental shelf from North Carolina to Florida, our observations of 7 species of sharks in videos from BRUVS deployed at a relatively small number of geographically restricted sites indicate that a targeted analysis, for sharks, of videos collected as part of the SERFS could provide critical information, without requiring extraction, for some of the 42 species $^{3}$ of sharks federally managed in the southeastern United States. Such an effort has the potential to provide estimates of relative abundance for assessments of shark stocks, improve predictions of spatiotemporal distribution, and aid in the identification of essential fish habitat for these important predators.

\section{Acknowledgments}

We thank N. Geraldi, D. Grenda, J. Hackney, M. Judge, G. Kellison, D. Meyer, and B. Teer for field assistance and the captain and crew of the M/V Spree. We acknowledge N. Bacheler, J. Carlson, A. Chester, A. Hohn, G. Kellison, K. Siegfried, and 3 anonymous reviewers for their comments on previous versions of this manuscript. Funding was provided by the Marine Fisheries Initiative of the National Marine Fisheries Service (grant no. 13MFIH0006).

\section{Literature cited}

Bacheler, N. M., and K. W. Shertzer.

2015. Estimating relative abundance and species richness from video surveys of reef fishes. Fish. Bull. 113:15-26. Crossref

Bacheler, N. M., D. J. Berrane, W. A. Mitchell, C. M. Schobernd, Z. H. Schobernd, B. Z. Teer, and J. C. Ballenger.

2014. Environmental conditions and habitat characteristics influence trap and video detection probabilities for reef fish species. Mar. Ecol. Prog. Ser. 517:1-14. Crossref

Bacheler, N. M., Z. H. Schobernd, D. J. Berrane, C. M. Schobernd, W. A. Mitchell, B. Z. Teer, K. C. Gregalis, and D. M. Glasgow.

2016. Spatial distribution of reef fish species along the Southeast US Atlantic Coast inferred from underwater video survey data. PLoS ONE 11(9):e0162653. Crossref

Bacheler, N. M., N. R. Geraldi, M. L. Burton, R. C. Muñoz, and G. T. Kellison.

2017. Comparing relative abundance, lengths, and habitat of temperate reef fishes using simultaneous underwater visual census, video, and trap sampling. Mar. Ecol. Prog. Ser. 574:141-155. Crossref

\footnotetext{
${ }^{3}$ Atlantic highly migratory species, Table 1 of Appendix A to part 635-oceanic sharks, 54 C.F.R. 635 (2018). [Available from website].
} 
Barley, S. C., M. G. Meekan, and J. J. Meeuwig.

2017. Species diversity, abundance, biomass, size and trophic structure of fish on coral reefs in relation to shark abundance. Mar. Ecol. Prog. Ser. 565:163-179. Crossref

Bond, M. E., E. A. Babcock, E. K. Pikitch, D. L. Abercrombie, N. F. Lamb, and D. D. Chapman.

2012. Reef sharks exhibit site-fidelity and higher relative abundance in marine reserves on the Mesoamerican Barrier Reef. PLoS ONE 7(3):e32983. Crossref

Brooks, E. J., K. A. Sloman, D. W. Sims, and A. J. Danylchuk. 2011. Validating the use of baited remote underwater video surveys for assessing the diversity, distribution and abundance of sharks in the Bahamas. Endanger. Spec. Res. 13:231-243. Crossref

Carlson, J. K., L. F. Hale, A. Morgan, and G. Burgess.

2012. Relative abundance and size of coastal sharks derived from commercial shark longline catch and effort data. J. Fish Biol. 80:1749-1764. Crossref

Colton, M. A., and S. E. Swearer.

2010. A comparison of two survey methods: differences between underwater visual census and baited remote underwater video. Mar. Ecol. Prog. Ser. 400:19-36. Crossref

De Vos, L., R. G. A. Watson, A. Götz, and C. G. Attwood.

2015. Baited remote underwater video system (BRUVs) survey of chondrichthyan diversity in False Bay, South Africa. Afr. J. Mar. Sci. 37:209-218. Crossref

Dulvy, N. K., S. L. Fowler, J. A. Musick, R. D. Cavanagh, P. M. Kyne, L. R. Harrison, J. K. Carlson, L. N. K. Davidson, S. V. Fordham, M. P. Francis, et al.

2014. Extinction risk and conservation of the world's sharks and rays. Elife 3:e00590. Crossref

Dulvy, N. K., C. A. Simpfendorfer, L. N. K. Davidson, S. V. Fordham, A. Brautigam, G. Sant, and D. J. Welch.

2017. Challenges and priorities in shark and ray conservation. Curr. Biol. 27:R565-R572. Crossref

Espinoza, M., M. Cappo, M. R. Heupel, A. J. Tobin, and C. A. Simpfendorfer.

2014 Quantifying shark distribution patterns and species-habitat associations: implications of marine park zoning. PLoS ONE 9(9):e106885. Crossref

Espinoza, M., E. J. I. Ledee, C. A. Simpfendorfer, A. J. Tobin, and M. R. Heupel.

2015 Contrasting movements and connectivity of reefassociated sharks using acoustic telemetry: implications for management. Ecol. Appl. 25:2101-2118. Crossref

Estes, J. A., J. Terborgh, J. S. Brashares, M. E. Power, J. Berger, W. J. Bond, S. R. Carpenter, T. E. Essington, R. D. Holt, J. B. C. Jackson, et al.

2011. Trophic downgrading of planet Earth. Science 333: 301-306. Crossref

Frisch, A. J., M. Ireland, J. R. Rizzari, O. M. Lonnstedt, K. A. Magnenat, C. E. Mirbach, and J. P. A. Hobbs.

2016. Reassessing the trophic role of reef sharks as apex predators on coral reefs. Coral Reefs 35:459-472. Crossref

Heithaus, M. R., A. Frid, J. J. Vaudo, B. Worm, and A. J. Wirsing.

2010. Unraveling the ecological importance of elasmobranchs. In Sharks and their relatives II: biodiversity, adaptive physiology, and conservation (J. C. Carrier, J. A. Musick, and M. R. Heithaus, eds.), p. 611-638. CRC Press, Boca Raton, FL.

Heupel, M. R., and C. A. Simpfendorfer.

2014. Importance of environmental and biological drivers in the presence and space use of a reef-associated shark. Mar. Ecol. Prog. Ser. 496:47-57. Crossref

Heupel, M. R., D. M. Knip, C. A. Simpfendorfer, and N. K. Dulvy.

2014. Sizing up the ecological role of sharks as predators. Mar. Ecol. Prog. Ser. 495:291-298. Crossref

Kulbicki, M.

1998. How the acquired behaviour of commercial reef fishes may influence the results obtained from visual censuses. J. Exp. Mar. Biol. Ecol. 222:11-30. Crossref

Langlois, T. J., E. S. Harvey, B. Fitzpatrick, J. J. Meeuwig, G. Shedrawi, and D. L. Watson.

2010. Cost-efficient sampling of fish assemblages: comparison of baited video stations and diver video transects. Aquat. Biol. 9:155-168. Crossref

Link, J., J. Burnett, P. Kostovick, and J. Galbraith.

2008. Value-added sampling for fishery independent surveys: don't stop after you're done counting and measuring. Fish. Res. 93:229-233. Crossref

MacNeil, M. A., N. A. J. Graham, M. J. Conroy, C. J. Fonnesbeck, N. V. C. Polunin, S. P. Rushton, P. Chabanet, and T. R. McClanahan.

2008. Detection heterogeneity in underwater visual-census data. J. Fish Biol. 73:1748-1763. Crossref

McCauley, D. J., K. A. McLean, J. Bauer, H. S. Young, and F. Micheli.

2012 Evaluating the performance of methods for estimating the abundance of rapidly declining coastal shark populations. Ecol. Appl. 22:385-392. Crossref

Meekan, M. G., and M. Cappo.

2004. Non-destructive techniques for rapid assessment of shark abundance in northern Australia, 36 p. Aust. Inst. Mar. Sci., Townsville, Australia.

Mitchell, W. A., G. T. Kellison, N. M. Bacheler, J. C. Potts, C. M. Schobernd, and L. F. Hale.

2014. Depth-related distribution of postjuvenile red snapper in southeastern US Atlantic Ocean waters: ontogenic patterns and implications for management. Mar. Coast. Fish. 6:142-155. Crossref

Murphy, H. M., and G. P. Jenkins.

2010. Observational methods used in marine spatial monitoring of fishes and associated habitats: a review. Mar. Freshw. Res. 61:236-252. Crossref

Nadon, M. O., J. K. Baum, I. D. Williams, J. M. McPherson, B. J. Zgliczynski, B. L. Richards, R. E. Schroeder, and R. E. Brainard.

2012. Re-creating missing population baselines for Pacific reef sharks Conserv. Biol. 26:493-503. Crossref

Osgood, G. J., and J. K. Baum.

2015. Reef sharks: recent advances in ecological understanding to inform conservation. J. Fish Biol. 87:1489-1523. Crossref

Peterson, C. D., C. N. Belcher, D. M. Bethea, W. B. Driggers III, B. S. Frazier, and R. J. Latour.

2017. Preliminary recovery of coastal sharks in the southeast United States. Fish Fish. 18:845-859. Crossref

Santana-Garcon, J., M. Braccini, T. J. Langlois, S. J. Newman, R. B. McAuley, and E. S. Harvey.

2014. Calibration of pelagic stereo-BRUVs and scientific longline surveys for sampling sharks. Methods Ecol. Evol. 5:824-833. Crossref

Schobernd, Z. H., N. M. Bacheler, and P. B. Conn.

2014. Examining the utility of alternative video monitoring metrics for indexing reef fish abundance. Can. J. Fish. Aquat. Sci. 71:464-471. Crossref 
SEDAR (Southeast Data Assessment and Review).

2017. SEDAR 54-Stock assessment report: HMS sandbar shark, 176 p. SEDAR, North Charleston, SC. [Available from website].

2013. SEDAR 34-Stock assessment report: HMS Atlantic sharpnose shark, 296 p. SEDAR, North Charleston, SC. [Available from website].

Stoner, A. W., B. J. Laurel, and T. P. Hurst.

2008. Using a baited camera to assess relative abundance of juvenile Pacific cod: field and laboratory trials. J. Exp. Mar. Biol. Ecol. 354:202-211. Crossref

Terborgh, J. W.

2015. Toward a trophic theory of species diversity. Proc. Natl. Acad. Sci. U.S.A. 112:11415-11422. Crossref

Tickler, D. M., T. B. Letessier, H. J. Koldewey, and J. J. Meeuwig.

2017. Drivers of abundance and spatial distribution of reef-associated sharks in an isolated atoll reef system. PLoS ONE 12(5):e0177374. Crossref

Ward-Paige, C. A.

2017. A global overview of shark sanctuary regulations and their impact on shark fisheries. Mar. Policy 82:8797. Crossref

Ward-Paige, C., J. M. Flemming, and H. K. Lotze.

2010. Overestimating fish counts by non-instantaneous visual censuses: consequences for population and community descriptions. PLoS ONE 5(7):e11722. Crossref Watson, D. L.

2006. Use of underwater stereo-video to measure fish assemblage structure, spatial distribution of fishes and change in assemblages with protection from fishing. Ph.D. diss., 188 p. Univ. Western Australia. Perth, Australia.

Watson, D. L., and E. S. Harvey.

2007. Behaviour of temperate and sub-tropical reef fishes towards a stationary SCUBA diver. Mar. Freshw. Behav. Physiol. 40:85-103. Crossref

Watson, D. L., E. S. Harvey, B. M. Fitzpatrick, T. J. Langlois, and G. Shedrawi.

2010. Assessing reef fish assemblage structure: how do different stereo-video techniques compare? Mar. Biol. 157:1237-1250. Crossref

White, E. R., M. C. Myers, J. M. Flemming, and J. K. Baum. 2015. Shifting elasmobranch community assemblage at Cocos Island-an isolated marine protected area. Conserv. Biol. 29:1186-1197. Crossref

White, J., C. A. Simpfendorfer, A. J. Tobin, and M. R. Heupel. 2013. Application of baited remote underwater video surveys to quantify spatial distribution of elasmobranchs at an ecosystem scale. J. Exp. Mar. Biol. Ecol. 448:281288. Crossref

Willis, T. J., R. B. Millar, and R. C. Babcock.

2000. Detection of spatial variability in relative density of fishes: comparison of visual census, angling, and baited underwater video. Mar. Ecol. Prog. Ser. 198:249-260. Crossref

Wirsing, A. J., M. R. Heithaus, and L. M. Dill.

2007. Can measures of prey availability improve our ability to predict the abundance of large marine predators? Oecologia 153:563-568. Crossref 